\title{
Who do We Listen to More: Opinion Leaders or Friends? The Social Function of Conformity Behavior in Social Commerce
}

\author{
Yanli Jia \\ Department of Marketing, School of Management, Xiamen University \\ yanli.xmu@gmail.com \\ Ivy L. B. Liu \\ Department of Information Systems and Logistics, Faculty of Business and Enterprise, Swinburne University of \\ Technology \\ liboliu@swin.edu.au
}

\begin{abstract}
Online social information (e.g., product ratings and product purchase) is widely available on the social commerce sites and is believed to affect user purchase decisions. Drawing from the prior research on online conformity, we examine any differential impact of the online social information generated by opinion leader versus friends. By analyzing a largescale data collected from a social commerce site, we found that user purchase decisions are influenced by the online social information both by opinion leaders and by friends. However, the information by friends has greater effect in comparison to that by opinion leaders. In addition, our results indicated that female users demonstrate greater tendency to conform to friends than opinion leaders, but not for male users. This study contributes to the existing literature by explaining how different types of social information influence users' purchase decision and identifying the moderating role of gender on it. The results offer important and interesting insights to research and practice.
\end{abstract}

Keywords: conformity behavior, gender, herding, opinion leader, social commerce, user purchase decision.

\section{Introduction}

Central to the study of online social networks has been the influence of others. That is, an individual will observe the referrals or actions of those behind him or her, and follow the referrals or behavior of the preceding individuals without regard to his or her own information. The common belief behind the conformity behavior is that people reshape their beliefs on the quality of different alternatives by observing others' decisions on these alternatives, thinking that "they must know better than I do in a given area."

In this paper, we attempt to revisit the popular belief that people like to conform to others. In particular, we focus on two types of "others"- online friends and opinion leaders, and compare people's different conformity behaviors toward them. Asch [2], in his seminal paper, has documented how individuals often succumb to peer pressure (mostly from friends) when making judgments. More recently, Feng, et al. [14] find that online friends exert conformity pressure, motivating consumers to generate similar product ratings. In the domain of movie industry, Lee, et al. [24] report the similar conformity phenomenon; that is, relative to prior ratings by strangers, friends' ratings always induce herding.

However, online friends are not the only group that people would like to follow. Opinion leaders could influence people's decision via multiple ways, such as online "tips" and product endorsements. Opinion leaders refer to a group who are normally interconnected and have a higher status, education, and social standing and thus exert a disproportionate amount of influence on social networks [26, 29]. One of the best examples of opinion leaders is the socalled Internet celebrities, who create original contents, including articles, photo and videos, to build a dedicated audience on social networking platforms. In the business world, their influence on audience can surely be put to commercial use. A Chinese Internet celebrity in fashion areas - Zhang Dayi, for instance, has approximately 4 million followings on Sina Weibo (i.e., a Chinese version of Twitter), and one of her product endorsements sends sales soaring - 5,000 garments in two seconds, 
equivalent to annual sales of a small bricks-andmortar store

(http://usa.chinadaily.com.cn/epaper/201603/16/content_23897504.htm).

Despite of the explosion of literature advocating the effectiveness of friends' influences [14, 24], the influence of opinion leaders has received very little attention in Information Systems (IS) literature, except a study by $\mathrm{Li}$ and $\mathrm{Du}$ [26]. However, their study that focused on how to identify opinion leaders on a social network did not shed light on how the online social information (e.g., product ratings and product purchase) generated by opinion leaders exerts an influence. Furthermore, the relative impact of opinion leaders' information and online friends' information on people's conformity behavior remains unknown.

To deal with these gaps in literature, we intend to answer the three questions as below in the present research:

1. How will the online social information generated by opinion leaders and online friends affect user's purchase decision?

2. Which type of online social information by opinion leaders versus by friends will exert a stronger influence on user's purchase decision?

3. How will gender moderate the effect of online social information on user's purchase decision?

To answer these research questions, we crawl data from a popular social commerce site in Asia, which provides an online platform where users can share their personal experience of using products with others. We believe the present work advances our knowledge in three perspectives. First, as stated earlier, prior work has mainly focused on the influence of online friends' prior purchase or ratings on people's conformity behavior. The present work, however, examines the influence of online social information from two sources - not only friends but also opinion leaders. Second, we empirically test the relative impact of these two types of online social information generated by opinion leaders versus friends, and delineate which one is more effective in stimulating user's purchase decision. In this way, our investigation provides actionable guidance for marketing practitioners to better manage and utilize online social information to increase sales. Finally, we notice that how people's gender moderates the influence of online social information cues on people's purchase behavior has been under investigated in the existing literatures. Thus, this study attempts to examine the moderating role of gender in relationship between prior information and user's purchase decision.
The reminder of this paper is structured as follows. First, we present the theoretical foundation of this research and introduce our research model. We then describe the methodology of the study and present the results of data analysis. Finally, we conclude with the discussion of the theoretical and practical implications, as well as the limitations of our work.

\section{Theoretical development and hypotheses}

\subsection{Online social information}

On the online social platforms (e.g., social networking sites and online shopping communities), online social information that is generated by prior users has been recognized as one of the most important information shaping current users' behaviors and decisions. Prior work [10] has identified two types of online social information, namely, action-based and opinion-based.

Action-based social information refers to the information inferred from others' actual behavior (e.g., sales and clicking numbers). Recent evidence [1, $21,28]$ has shown that people are strongly affected by others so that they tend to mimic others' decisions and choices to behave efficiently (so-called herding behavior). Under our research paradigm (i.e., social commerce sites), sales information might serve as the best representative of action-based social information.

Opinion-based social information refers to the information that reflects people's general assessment of a product's qualities. One of the most common examples is online product review (i.e., electronic word-of-mouth). The common belief behind the relationship between online reviews and sales is that potential consumers could acquire information about the product or the vendor from the information so that reviews influence sales in a consistent manner. Therefore, a considerable amount of research has paid the primary attention to the product information contained in reviews $[12,23]$. However, in comparison to detailed information contained in reviews, the product rating information provides more direct and observable cues to a product's qualities. It has long been believed that people attend and respond much more to the information that is salient and observable than to information that is not $[17,27]$. Therefore, we believe the information of product ratings, rather than the detailed review information, serves as a better representative of opinion-based social information.

To sum up, in the present research, we tend to focus on the two types of social information - 
product ratings and sales, and examine how the information generated by others affects users' decision and behavior.

\subsection{Online conformity}

Online conformity is defined as online users' disposition to conform to a single, homogeneous standard of behavior (i.e. social norm) despite heterogeneous underlying preferences [6]. Prior research in economics, social psychology, information systems and marketing has provided converging evidence that people tend to conform to others' choices. Two reasons have been identified to explain why conformity behavior occurs: social and informational [20].

First, literature on information-motivated herding behavior suggests that a driving force of conformity is to avoid the competitive disadvantages arising from rejecting others' choices [4, 8]. The implication of these studies may be that people like to conform to others' choices for informational reasons, as such people follow others' decisions when they believe the information held by others is valid and will help them avoid the worst-case scenarios. Consequently, people tend to rely on others' ratings to make better choice and this is especially the case when they are uncertain about the quality of products [13]. Notably, this relationship is a typical "one-way" information focused relationship [14]. In this relationship, users should pay more attention to and conform more to the individuals who could provide more diagnostic knowledge in a given area. Relative to opinion leaders, online friends share more common characteristics and personal interest, which might lead people to develop similar attitudes and behavior [22]. In this sense, information from online friends is more diagnostic than that from opinion leaders and should facilitate more conformity.

Alternatively, conformity behaviors are also likely to occur for social purpose. Past research has shown that people tend to conform to others to facilitate social affiliation [5, 19], and avoid being dislike, rejected, and even unwanted [25, 30]. Consequently, individuals who have been socially excluded are tempted to seek similarity and conformity to others to reduce the chance of rejection and ostracism [9, 16], and people who possess social power and thus do not need to rely on others indicate lower preference for conformity [15]. Obviously, this relationship is represented as a "two-way" structure [14]. If this is the case, consumers will conform more to the online friends' choices than the opinion leaders, for their relationship with the opinion leader is typically "one-way" and there is no reason to expect conformity to opinion leaders will help to establish and develop social ties.

Although the majority of prior research in information systems has supported the informational function of conformity behavior, this research posits that conformity behavior also occurs for social reasons. Moreover, either from the social aspect or from the informational aspect, information from online friends wins and simulates more conformity than information from opinion leaders. Therefore, we formally state our hypothesis as below.

H1: Online friends' product rating will exert a stronger influence on user purchase decision than will opinion leaders'.

H2: Online friends' purchase behavior will exert stronger influence on user purchase decision than will opinion leaders'.

\subsection{The moderating role of gender}

Bakan (1966) found that females and males pay different attentions to social relationships. Specifically, females attend to communal goals that are primarily focused on social relationships and the coexistence of the self and others, whereas males are influenced by agentic goals that are primarily focused on the self [3]. To this end, females tend to conform more to online friends than to opinion leaders, because friend relationship typically requires mutual consent and the obligation to reciprocate, which better satisfies females' social needs. However, as males are not motivated to develop and maintain social ties, their preference for online friends' choices and opinion leaders' choices should not differ. We formally state our hypotheses as below

H3: Gender will moderate the effect indicated in H1. That is, female consumers demonstrate greater tendency to follow common friends' product rating than male consumers.

H4: Gender will moderate the effect indicated in H2. That is, female consumers demonstrate greater tendency to follow common friends' purchase behavior than male consumers.

Figure 1 depicts the research model for this study. 


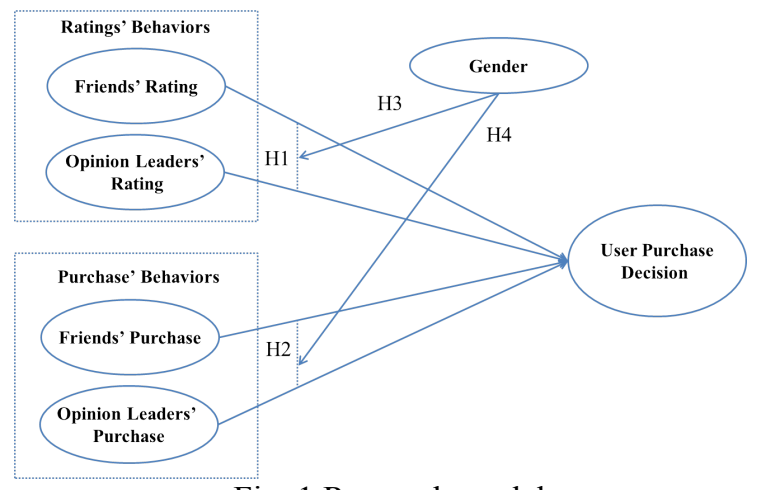

Fig. 1 Research model

\section{Research Method}

\subsection{Data Collection}

The data for this study were crawled during the month of Nov 2012 from a social commerce site in Asia, which provides a platform for users to share their experience, and to interact with other users. We randomly selected 13,066 users including 6,533 male users and 6,533 female users.

Users in the social commerce site can post the experience that they have had with the use of any product, provide a rating (from 1 to 7 ) on the product, and share the products that they have purchased by adding products to their "buy-lists". Users can also choose to "follow" other users whose posts or ratings are useful in the social commerce site. The following relationship does not need mutual consent, nor has to be reciprocal. The number of followings a user has indicates his/her immersion in the social commerce site. The number of followers a user has indicates his/her popularity. Furthermore, the social commerce site enables users to observe following users' behaviors (i.e., purchase behavior and rating behavior). Figure 2 shows the social network structure of ego user in the social commerce site.

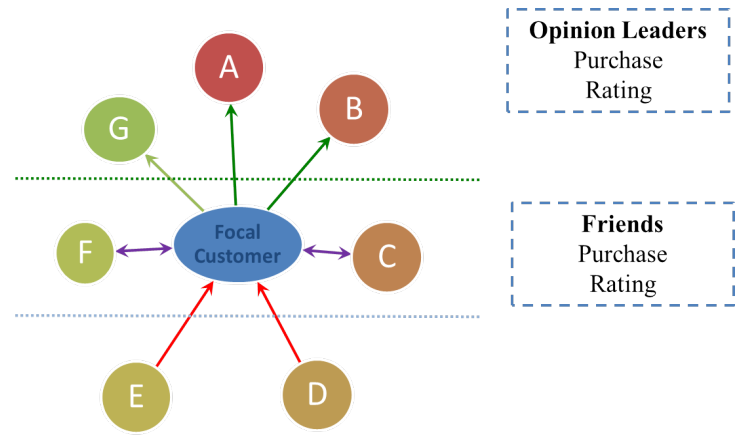

Fig. 2 Social network structure of ego user
In this study, we aim to explore how a user's purchase decision is influenced by other users' product rating and product purchase, including friends and opinion leaders. Based on users ID, we crawled the network data for each user. Specifically, we collected the "following" (i.e., opinion leaders), "friends" and "followers" of users' lists and built an egocentric network for each user. Then we crawled friends-based behavior (i.e., friends' rating and friends' purchase) and opinion leaders-based behavior (i.e., opinion leaders' rating and opinion leaders' purchase).

\subsection{Operationalization of Constructs}

The constructs included in the research model are operationalized as follows.

Opinion leaders' rating is operationalized as the total score of ratings (on products) provided by user' followings (exclude reciprocal following relationship). To provide support for the hypothesized causal influence of opinion leaders on user purchase decision, we only included ratings that had been provided by a user's followings before a product was added to the user's "buy-list".

Friends' rating is operationalized as the total score of ratings provided by individuals who are reciprocal followed by a user, or the user's friends. Similar care was taken to ensure that we only included ratings that had been provided by a user's friends before a product was added to the user's "buy-list".

Opinion leaders' purchase is operationalized as the total number of products in the buy-lists of a user's followings in the social commerce site. Similar care was taken to ensure that we took into account only products added to the followings' "buy-lists" before a product was added to the user's own "buylist".

Friends' purchase is operationalized as the total number of products in the buy-lists of a user's friends in the social commerce site. Similar care was taken to ensure that we took into account only products added to the friends" "buy-lists" before a product was added to the user's own "buy-list".

User purchase decision is operationalized as the number of products in a user's buy-list. Such operationalization was considered because consumers can add products to their buy-lists to indicate that they have already bought specific products in the social commerce site.

\begin{tabular}{|c|c|c|c|c|}
\hline Parameters & Min & $\operatorname{Max}$ & Mean & SD \\
\hline Friends' rating & 0 & 941 & 1.937 & 23.266 \\
\hline Opinion leaders' rating & 0 & 542 & 1.160 & 15.332 \\
\hline Friends' purchase & 0 & 666 & 0.758 & 9.416 \\
\hline $\begin{array}{l}\text { Opinion leaders' } \\
\text { purchase }\end{array}$ & 0 & 585 & 0.458 & 7.207 \\
\hline
\end{tabular}




\section{Data Analysis}

Table 1 summarizes the descriptive statistics for

\section{Table 2 Results of Regression Analysis}

\begin{tabular}{|l|l|l|l|l|}
\hline Parameters & \multicolumn{2}{|l|}{$\begin{array}{l}\text { Unstandardized } \\
\text { Coefficients }\end{array}$} & \multicolumn{2}{l|}{ Hypothesis Test } \\
\cline { 2 - 5 } & $\mathrm{B}$ & $\begin{array}{l}\text { Std. } \\
\text { Error }\end{array}$ & $\begin{array}{l}\text { Wald } \\
\text { Chi- } \\
\text { Square }\end{array}$ & Sig. \\
\hline Friends' rating & 0.012 & 0.0011 & 118.707 & .000 \\
\hline $\begin{array}{l}\text { Opinion leaders' } \\
\text { rating }\end{array}$ & 0.008 & 0.0011 & 46.685 & .000 \\
\hline $\begin{array}{l}\text { Friends' } \\
\text { purchase }\end{array}$ & 0.100 & 0.0031 & 1005.521 & .000 \\
\hline $\begin{array}{l}\text { Opinion leaders' } \\
\text { purchase }\end{array}$ & 0.024 & 0.0026 & 88.708 & .000 \\
\hline $\begin{array}{l}\text { Omnibus Test: Likelihood Ratio Chi-Square }= \\
8771.705 \text { (df =4, p < 0.0001) }\end{array}$ \\
\hline
\end{tabular}

each variable. In this study, we adopted an empirical analysis approach and collected objective usage data from 13,066 members in a social commerce site.

User purchase decision is represented using a count variable summing up all the products. Negative binomial regression is often used to analyze count data. Therefore, in this study, negative binomial regression (using SPSS) was adopted to test the model.

\subsection{Main effect}

A negative binomial regression analysis was performed with consumer purchase decision as dependent variable, opinion leaders' rating and purchase, and friends' rating and purchase as independent variables. The results are presented in table 2 and figure 3, which summarizes the Omnibus test results, coefficients, the Wald statistic, and associated degrees of freedom and significance level of each of the predictor.

Omnibus test reveals that the full model significantly predicts user purchase decision $($ Likelihood Ratio Chi-Square $=8771.705, \mathrm{df}=4, \mathrm{p}<$
0.0001). Opinion leaders' rating and purchase have significant positive effect on user purchase decision $(\beta=0.008, \mathrm{p}<0.0001 ; \beta=0.024, \mathrm{p}<0.0001)$. Friends' rating and purchases also have significant positive effect on user purchase decision $(\beta=0.012$, $\mathrm{p}<0.0001 ; \beta=0.100, \mathrm{p}<0.0001)$, suggesting that the greater the number of product ratings provided and prior purchases made by a user's followings and friends, the more likely the user will purchase products.

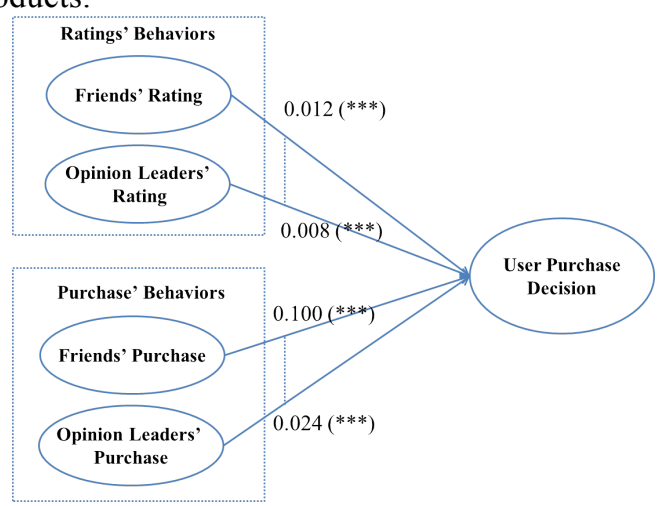

Fig. 3 Main effect of research model

A comparison of the two $\beta$ coefficients reveals that friends' rating is the more influential predictor than opinion leaders' rating on user purchase decision (Wald $\mathrm{t}=2.571, \mathrm{p}<0.050$ ). Thus, $\mathrm{H} 1$ is supported. Moreover, a comparison of the two $\beta$ coefficients reveals that friends' purchases is the more influential predictor than opinion leaders' purchase (Wald $\mathrm{t}=$ 18.785, $\mathrm{p}<0.001$ ), suggesting that a user will refer more to her or his friends' prior purchase behavior than their opinion leaders' prior purchase behavior when making her or his own purchase decisions. Thus, H2 is supported.

\subsection{Between-group differences comparison}

To test $\mathrm{H} 3$ and $\mathrm{H} 4$, we conduct between-group differences comparison. The between-group differences were calculated with a t-test (Qureshi and Compeau, 2009), by comparing the path coefficients

\section{Table 3 Results of Regression Analysis for Female and Male Users}

\begin{tabular}{|c|c|c|c|c|c|c|c|c|}
\hline \multicolumn{5}{|l|}{ Male users } & \multicolumn{4}{|c|}{ Female users } \\
\hline \multirow[t]{2}{*}{ Parameters } & \multicolumn{2}{|c|}{$\begin{array}{l}\text { Unstandardized } \\
\text { Coefficients }\end{array}$} & \multicolumn{2}{|c|}{ Hypothesis Test } & \multicolumn{2}{|c|}{$\begin{array}{l}\text { Unstandardized } \\
\text { Coefficients }\end{array}$} & \multicolumn{2}{|c|}{ Hypothesis Test } \\
\hline & B & $\begin{array}{l}\text { Std. } \\
\text { Error }\end{array}$ & $\begin{array}{l}\text { Wald Chi- } \\
\text { Square }\end{array}$ & Sig. & $\mathrm{B}$ & Std. Error & $\begin{array}{l}\text { Wald Chi- } \\
\text { Square }\end{array}$ & Sig. \\
\hline $\begin{array}{l}\text { Friends' } \\
\text { rating }\end{array}$ & 0.001 & 0.0012 & 0.811 & .368 & 0.019 & 0.0023 & 65.418 & .000 \\
\hline $\begin{array}{l}\text { Opinion } \\
\text { leaders' rating }\end{array}$ & 0.002 & 0.0020 & 0.937 & .333 & 0.009 & 0.0014 & 39.783 & .000 \\
\hline $\begin{array}{l}\text { Friends' } \\
\text { purchase }\end{array}$ & 0.059 & 0.0031 & 370.407 & .000 & 0.159 & 0.0083 & 368.802 & .000 \\
\hline $\begin{array}{l}\text { Opinion } \\
\text { leaders' } \\
\text { purchase }\end{array}$ & 0.051 & 0.0036 & 200.944 & .000 & 0.015 & 0.0045 & 11.282 & .001 \\
\hline
\end{tabular}


for male and female. The results are presented in figure 3 and figure 4.

A comparison of the two $\beta$ coefficients reveals that friends' rating and opinion leaders' rating has similar influence on user purchase decision (Wald $\mathrm{t}=$ $0.429, \mathrm{p}>0.100$ ) for male users. Moreover, friends' purchases and opinion leaders' purchases has similar influence on user purchase decision for male users (Wald $\mathrm{t}=1.604, \mathrm{p}>0.050$ ).

A comparison of the two $\beta$ coefficients reveals that friends' rating is the more influential predictor than opinion leaders' rating on user purchase decision for female users (Wald $\mathrm{t}=3.714, \mathrm{p}<0.001$ ). Moreover, friends' purchase is the more influential predictor than opinion leaders' purchase for female users (Wald $\mathrm{t}=15.253, \mathrm{p}<0.001)$.

The results indicated that female users demonstrate greater tendency to follow friends' review, but not for male users. Their effects were significantly different. Gender moderate the effect indicated in H1. Thus H3 was supported. In addition, female users have greater tendency to follow friends' purchase, but nor for male users. The effects between male and female users were different. Gender moderate the effect indicated in $\mathrm{H} 2$. Thus $\mathrm{H} 4$ was supported.

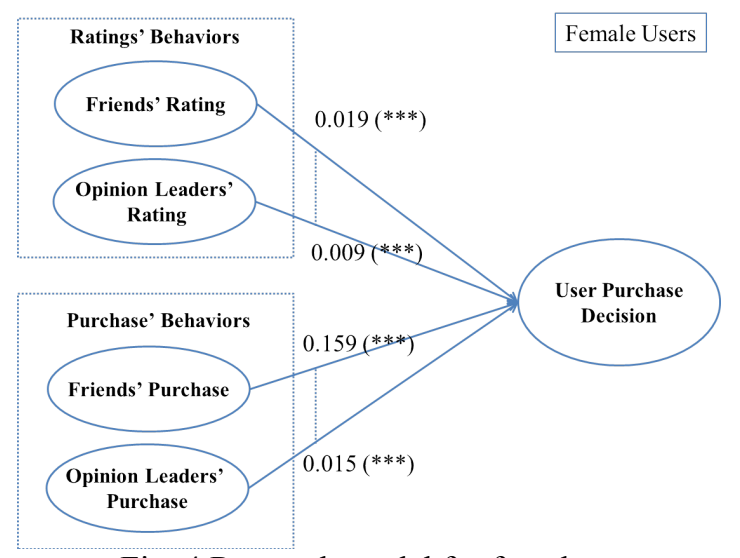

Fig. 4 Research model for female users

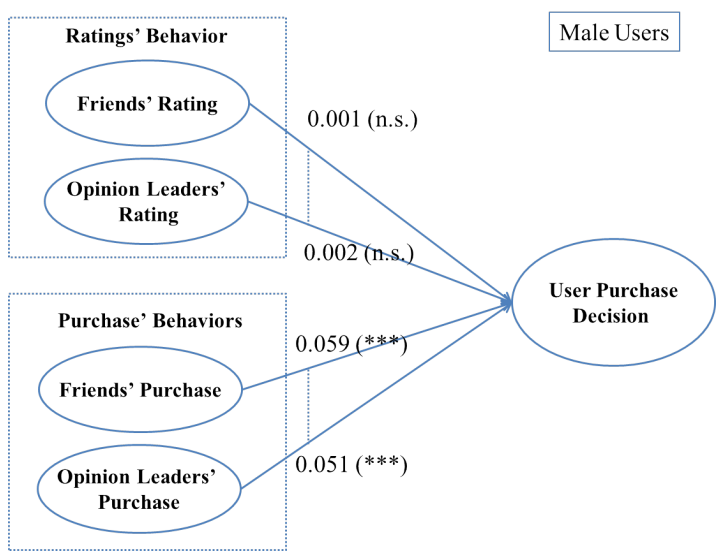

Fig. 5 Research model for male users

\section{Discussions and implications}

\subsection{Major findings}

Online conformity behavior has been one of the most important and fruitful conceptual formations of the last decades, in the realm of social psychology, economics and information systems. We study the influence of prior information by others on conformity behavior and, in particular, examine any differential impact of prior ratings/purchase behaviors by opinion leaders versus friends. We find that, relative to the opinion leaders' prior purchase, friends' purchase better predicts subsequent purchase behaviors. Similarly, friends' ratings are more influential than opinion leaders' ratings in determining subsequent purchase. Finally, relative to male users, female users reflect greater tendency to follow friends' purchase behavior.

\subsection{Theoretical implications}

The present research advances our knowledge in the extant literature in three perspectives. First of all, a great deal of prior research has mainly focused on the informational function of conformity behavior. For instance, observational learning literature has conceptualized conformity behavior as a result of an individual's rational decision to follow the behavior of preceding individuals without regard to his or her own information. This leads to informational cascades [8], and herding forms through such cascades [4, 7]. However, the present research intends to consider the social aspects associated with imitation behavior. That is, individuals tend to conform to others' actions to make themselves desirable to the targeted people and subsequently build or maintain intimate social relationships. 
Second, previous research on herding behavior has paid special attention to the relative impact of prior information by strangers versus friends on imitation behavior. Results show that information by friends (relative to crowd information) induces more herding [24]. However, we study any differential impact of prior information by opinion leaders versus friends and find that although the information by opinion leaders could to some extent guide individuals' purchase decision, the information by online friends serves as a better predictor. Finally, to the best of our knowledge, the present investigation is one of the most pioneering works that takes gender into consideration in the domain of online conformity. Our finding that female users demonstrate greater tendency to follow friends' information than opinion leaders provide further support for the social function of conformity behaviors.

\subsection{Managerial implications}

The findings of this study can help website designers by providing a more accurate and comprehensive understanding of the effects that how consumers' purchase behavior influence on users' purchase decision. Cheung, et al. [10] indicated that consumers' purchase behavior is more important consumers' rating, and thus some websites have designed the function to show other consumers' purchase (i.e., taobao.com). We further suggest that social commerce sites distinguish between the two types of information (i.e., from friends and from opinion leaders) and think about more effective procedures to display to users about the information that is more diagnostic for their decisions. For example, friends' behavior is more valuable comparing with opinion leaders' behavior. Therefore, website designers should highlight purchase behavior from friends rather than from opinion leaders. Moreover, the results of this study also show that, friends' purchases and reviews are more influential to female users rather than male users. A strategy then would be to expose those behaviors, website designers should design different views for female and male users. For example, for female users website designers should design layouts that highlight different information cues for opinion leaders' behavior and friends' behavior.

\subsection{Limitations}

In the current study, we used field data to examine the different effects of friends' and opinion leaders' ratings and prior purchase behavior on users purchase decision, through conformity behavior perspective. Each methodology has its pros and cons. There are a number of limitations to this research. First, this study collected data from a social commerce community, which focuses on fashion and beauty products, which are primarily hedonic $[11,18]$. Thus, caution is advised in generalizing the results of this study to other online communities that focus on utilitarian products, such as notebooks. Second, this study measured the friends' and opinion leaders' ratings and prior purchase behavior using aggregated data. Future study could use social network analysis to explore how network structure (e.g., strong tie and weak tie) influence users' purchase behavior. We expect users might develop different reactions to close friends and casual friends, and a further investigation regarding the relative impact of information from these two types of friends seems to suggest a fruitful research direction. Third, given that online friends and opinion leaders might generate idiosyncratic ratings and purchase, which might confound the observed effect, lab experiments seem to better deal with the potential confounding. Researchers may collect data about the time users spend browsing content to quantify imitation behavior. An eye tracking technique can be used to measure the way users browse the content from friends and opinion leaders. Fourth, the current study only considers gender as a moderator. More variables of demographic information (i.e., age) should be considered in the future study.

\subsection{Conclusions}

In the current study, we examined the relative effects of two different types of user behaviors (i.e., opinion leaders' behavior and friends' behavior) on user purchase decisions, and the moderating role of gender. The results of this study showed that friends' purchase behavior has greater effect on users' purchase decision comparing to opinion leaders' purchase behavior. Moreover, female users demonstrate greater tendency to follow friends' behavior, but not for male users. This study contributes to the existing literature by offering important and interesting insights to research and practice.

\section{References}

[1] S. Aral, L. Muchnik and A. Sundararajan, "Distinguishing influence-based contagion from homophily-driven diffusion in dynamic networks", Proceedings of the National Academy of Sciences, 106 (2009), pp. 21544-21549. 
[2] S. E. Asch, "Studies of independence and conformity: I. A minority of one against a unanimous majority", Psychological monographs: General and applied, 70 (1956), pp. 1.

[3] D. Bakan, "The duality of human existence: An essay on psychology and religion", (1966).

[4] A. V. Banerjee, "A simple model of herd behavior", The Quarterly Journal of Economics (1992), pp. 797-817.

[5] R. F. Baumeister and M. R. Leary, "The need to belong: desire for interpersonal attachments as a fundamental human motivation", Psychological bulletin, 117 (1995), pp. 497.

[6] B. D. Bernheim, "A theory of conformity", Journal of political Economy (1994), pp. 841-877.

[7] S. Bikhchandani, D. Hirshleifer and I. Welch, "Learning from the behavior of others: Conformity, fads, and informational cascades", The Journal of Economic Perspectives, 12 (1998), pp. 151-170.

[8] S. Bikhchandani, D. Hirshleifer and I. Welch, "A theory of fads, fashion, custom, and cultural change as informational cascades", Journal of political Economy (1992), pp. 992-1026.

[9] M. B. Brewer, "The social self: On being the same and different at the same time", Personality and social psychology bulletin, 17 (1991), pp. 475-482.

[10] C. M. Cheung, B. S. Xiao and I. L. Liu, "Do actions speak louder than voices? The signaling role of social information cues in influencing consumer purchase decisions", Decision Support Systems, 65 (2014), pp. 50-58. [11] R. Dhar and K. Wertenbroch, "Consumer choice between hedonic and utilitarian goods", Journal of marketing research, 37 (2000), pp. 60-71.

[12] W. Duan, B. Gu and A. B. Whinston, "Informational cascades and software adoption on the internet: an empirical investigation", Mis Quarterly (2009), pp. 23-48.

[13] U. Dulleck and R. Kerschbamer, "On doctors, mechanics, and computer specialists: The economics of credence goods", Journal of Economic literature (2006), pp. $5-42$.

[14] Y. K. Feng, C. A. Wang and M. Zhang, "The Impacts of Informant and Friend Relationships on Online Opinion Sharing", (2013).

[15] A. D. Galinsky, J. C. Magee, D. H. Gruenfeld, J. A. Whitson and K. A. Liljenquist, "Power reduces the press of the situation: implications for creativity, conformity, and dissonance", Journal of personality and social psychology, 95 (2008), pp. 1450.

[16] V. Griskevicius, N. J. Goldstein, C. R. Mortensen, R. B. Cialdini and D. T. Kenrick, "Going along versus going alone: when fundamental motives facilitate strategic (non) conformity", Journal of personality and social psychology, 91 (2006), pp. 281.

[17] F. Heider, The psychology of interpersonal relations, Psychology Press, 2013.

[18] M. B. Holbrook and E. C. Hirschman, "The experiential aspects of consumption: Consumer fantasies, feelings, and fun", Journal of consumer research (1982), pp. 132-140.

[19] Y. Hong, N. Huang, G. Burtch and C. Li, "Culture, Conformity and Emotional Suppression in Online
Reviews", Journal of the Association for Information Systems, forthcoming (2016).

[20] X. I. Huang, M. Zhang, M. K. Hui and R. S. Wyer Jr, "Warmth and conformity: The effects of ambient temperature on product preferences and financial decisions", Journal of Consumer Psychology (2013).

[21] R. Iyengar, C. Van den Bulte and T. W. Valente, "Opinion leadership and social contagion in new product diffusion", Marketing Science, 30 (2011), pp. 195-212.

[22] L. Jussim and D. W. Osgood, "Influence and similarity among friends: An integrative model applied to incarcerated adolescents", Social Psychology Quarterly (1989), pp. 98-112.

[23] D. S. Kostyra, J. Reiner, M. Natter and D. Klapper, "Decomposing the effects of online customer reviews on brand, price, and product attributes", International Journal of Research in Marketing (2015).

[24] Y.-J. Lee, K. Hosanagar and Y. Tan, "Do I follow my friends or the crowd? Information cascades in online movie ratings", Management Science, 61 (2015), pp. 2241-2258.

[25] J. M. Levine, "Reaction to opinion deviance in small groups", Psychology of group influence, 2 (1989), pp. 187231.

[26] F. Li and T. C. Du, "Who is talking? An ontologybased opinion leader identification framework for word-ofmouth marketing in online social blogs", Decision Support Systems, 51 (2011), pp. 190-197.

[27] R. E. Nisbett and L. Ross, "Human inference: Strategies and shortcomings of social judgment", (1980).

[28] P. M. Simpson, J. A. Siguaw and J. W. Cadogan, "Understanding the consumer propensity to observe", European Journal of Marketing, 42 (2008), pp. 196-221.

[29] A. Wang, M. Zhang and I.-H. Hann, "Socially Nudged: A Quasi-Experimental Study of Friends' Social Influence in Online Product Ratings", Information Systems Research, forthcoming (2015).

[30] R. S. Wyer Jr, "Effects of incentive to perform well, group attraction, and group acceptance on conformity in a judgmental task", Journal of Personality and Social Psychology, 4 (1966), pp. 21. 